\title{
Ultraviolet light exposure, skin cancer risk and vitamin D production
}

\author{
MIGUEL RIVAS $^{1}$, ELISA ROJAS ${ }^{1}$, MARÍA C.ARAYA ${ }^{2}$ and GLORIA M. CALAF ${ }^{3,4}$ \\ ${ }^{1}$ Department of Physics, Laboratory of Ultraviolet Sunlight Radiation, Faculty of Science, University of Tarapacá; \\ ${ }^{2}$ Servicio de Dermatología, Hospital Regional Dr. Juan Noé Crevani; ${ }^{3}$ Institute for Advanced Research, University of Tarapacá, \\ Arica 8097877, Chile; ${ }^{4}$ Center for Radiological Research, Columbia University Medical Center, New York, NY 10032, USA
}

Received July 24, 2014; Accepted April 8, 2015

DOI: $10.3892 / \mathrm{ol} .2015 .3519$

\begin{abstract}
The danger of overexposure to solar ultraviolet radiation has been widely reviewed since the 1980 s due to the depletion of the ozone layer. However, the benefits of mild exposure of the skin to ultraviolet (UV) light have not been widely investigated. Numerous reports have demonstrated that an association exists between low light exposure to the sun, non-melanoma skin cancer and a lack of vitamin D synthesis. As vitamin D synthesis in the body depends on skin exposure to UVB radiation from the sun (wavelength, 290-320 nm), experimental measurements for this type of solar radiation are important. The present study analyzed data obtained from a laboratory investigating UV radiation from the sun at the University of Tarapacá (Arica, Chile), where systematic experimental UVB measurements had been performed using a calibrated biometer instrument since 2006. These data were compared with skin cancer data from the local population. The results demonstrated that the incidence of skin cancer systematically increased from 7.4 to 18.7 in men and from 10.0 to 21.7 in women between 2000 and 2006 in Arica, respectively; this increase may be due to multiple factors, including the lack of adequate levels of vitamin D in risk groups such as post-menopausal women and senior age. This marked increase may also be due to the high levels of UV radiation measured in this region throughout the year. However, it is not certain that the local population has adequate vitamin D levels, nor that their skin has been predominantly exposed to artificial light that does not allow adequate vitamin $\mathrm{D}$ synthesis. Thus, the current study presents the association between skin type IV, the time to induce solar erythema and the time required to produce 1,000 international units of vitamin D.
\end{abstract}

Correspondence to: Dr Gloria M. Calaf, Institute for Advanced Research, University of Tarapacá, 1520 Antofagasta Street, Arica 8097877, Chile

E-mail: gmc24@columbia.edu

Key words: vitamin D, skin cancer, ultraviolet light

\section{Introduction}

Exposure to ultraviolet radiation (UV) from the sun has negative effects on human health due to its carcinogenic effects on the skin (1). However, low skin exposure to UVB radiation (wavelength, 290-320 $\mathrm{nm}$ ) from the sun due to environmental factors or the specific behavior an individual may also have negative outcomes (1). Vitamin D synthesis predominantly depends on the level of UVB sun radiation that the skin receives, with a lack of vitamin D in the body resulting in negative effects on overall health, muscle function and bone strength (2). In addition, vitamin D is associated with preventing type 1 diabetes and heart-associated diseases (2). Therefore, it is important to quantify the required time to synthesize adequate vitamin $\mathrm{D}$ levels from UVB radiation penetrating the skin $(2,3)$.

It is possible to determine the time required to synthesize adequate vitamin D levels in an organism depending on skin type by using experimental solar UV index (UVI) measurements (3). Sufficient levels of vitamin D are associated with multiple benefits in humans, including providing protection against different types of cancer, including colon (4), prostatic (5) and stomach cancer. Evidence of these associations has been provided by epidemiological studies performed in Northern hemisphere populations $(6,7)$. In addition, it has been identified that vitamin $\mathrm{D}$ has a positive effect on controlling high blood pressure (8); in humans, blood pressure decreases when vitamin D levels are at a suitable level. Furthermore, an adequate level of vitamin D is a reduction factor for autoimmune diseases, including multiple sclerosis, type 1 diabetes, rheumatoid arthritis, autoimmune disease of the thyroid and inflammatory bowel disease (9).

Humans depend on vitamin D synthesized from sunlight radiation to maintain calcified skeletons; however, a small quantity of vitamin D remains in the skin (10-13). This vitamin $\mathrm{D}$ is activated by interaction with the vitamin $\mathrm{D}$ receptor to control cell proliferation using a variety of strategies, such as interacting with long non-coding RNAs to reduce the risk of photocarcinogenesis $(11,12)$. In addition, vitamin $\mathrm{D}$ has a clearly defined role in phosphorus, calcium and bone metabolism (13-16). UV radiation has been demonstrated to be carcinogenic and responsible for the onset of the 
majority of types of skin cancer (13-15). Therefore, the population should be warned about misleading advertising from the tanning industry. The aim of the present study was to determine the required time to induce solar erythema $\left(\mathrm{T}_{\mathrm{Ery}}\right)$ for skin type IV and the required time to produce 1,000 international units (IU) of vitamin $\mathrm{D}\left(\mathrm{T}_{\mathrm{VitD}}\right)$.

\section{Materials and methods}

Location of the study. Arica is a city located in a subtropical area in the northernmost region of Chile. Arica has a microclimate with fairly stable meteorological conditions throughout the year, including a lack of rainfall $(<5 \mathrm{~mm}$ a decade), predictable winds and a high percentage of sunny days per year $(15,16)$. In addition, Arica is a desert area with vast sand and sea surfaces as well as scarce vegetation; therefore, Arica has high ground reflectivity $(14,15)$. The city is located at sea level and due to the good climate conditions, the population perform numerous outdoor recreational activities. $(16,17)$.

Measuring UVB sunlight radiation. A UVB sun device, which has been in used at the UV Sunlight Radiation Laboratory of Tarapacá University (Arica, Chile) since September 2006, was used in the present study. It is located $25 \mathrm{~m}$ above sea level, at a latitude of $18^{\circ} 49^{\prime} \mathrm{S}$ and longitude of $70^{\circ} 19^{\prime} \mathrm{W}$ on the uppermost part of the building with no elements blocking incoming sunlight radiation. Erythemal $\mathrm{UV}$ irradiance $\left(\mathrm{UV}_{\mathrm{Ery}}\right)$ was measured using a calibrated high-range YES-UVB-1 biometer (serial no. 090710, Yankee Environmental Systems, Inc., Turners Falls, MA, USA) through an agreement between Tarapacá University and the Chilean Meteorological Department (CMD, Santiago, Chile). Measurements obtained from the device were incorporated in real-time using a UVB device network installed by the CMD. Thus, the device was connected to the UVB sun-measuring network of Chile, covering an area between Arica and the Antarctic territory in the South of Chile. All devices used in the present study complied with the World Meteorological Organization calibration specifications (18).

Calculation of $U V$ index and related calculations. The solar UVI $\left(\mathrm{W} / \mathrm{m}^{2}\right)$ was calculated from the collected $\mathrm{UV}_{\text {Ery }}$ biometer data by multiplying $\mathrm{UV}_{\text {Ery }}$ by 40 (11). Subsequently, the $\mathrm{T}_{\text {Ery }}[1$ minimal erythemal dose (MED)] was calculated using the following equation: $\mathrm{T}_{\mathrm{Ery}}=(4,000 / 60) \times[(\mathrm{MED} \times$ sun protection factor $\left.) / \mathrm{UVI})\right]$, where MEDF depends on the Fitzpatrick classification of skin types $(19,20)$. In the present study, the cohort included individuals with MED skin type IV $\left(0.40-0.60 \mathrm{~kJ} / \mathrm{m}^{2} /\right.$ day $)$. The cohort used in this study has been further described previously (15).

$\mathrm{UV}_{\text {Ery }}$ is expressed as the standard erythemal dose (SED) required to induce erythema, where $1 \mathrm{SED}=100 \mathrm{Jm}^{-2} \mathrm{UV}_{\mathrm{Ery}}$. From the $\mathrm{UV}_{\text {Ery }}$ biometer measurement, vitamin D UV irradiation $\left(\mathrm{UV}_{\mathrm{VitD}}\right)$ was estimated using a tropospheric UV model (21). Ozone layer data were obtained from NASA/TOMS measurements by using the User's Guide from National Aeronautics and Space Administration (NASA) (22). The subsequent calculation for TVitD was obtained from Mckenzie et al (3). The most common skin types in chilean teenagers of low social economical strata that have been analyzed in previous studies (14-16)

\section{Ultraviolet solar index and UV quotient}

A

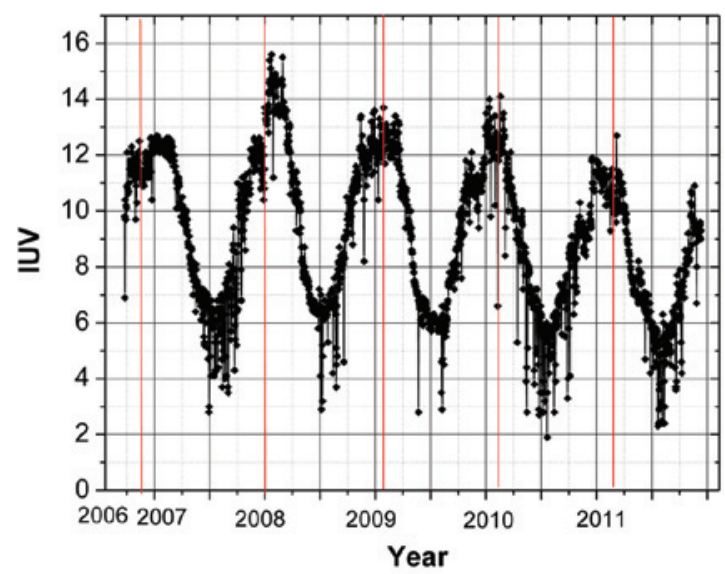

B

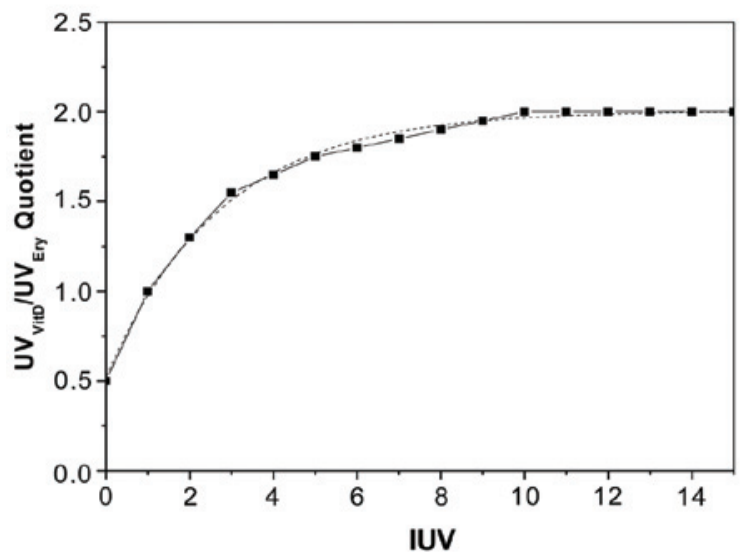

Figure 1. (A) UVI levels per Julian day, obtained in Arica between 2006 and 2011. (B) Quotients of $U V_{\text {VitD }} / U_{\text {Ery }}$ as a function of UVI. UVI, ultraviolet index; $\mathrm{UV}_{\mathrm{VitD}}$, vitamin $\mathrm{D}$ ultraviolet irradiation; $\mathrm{UV}_{\mathrm{Ery}}$, erythemal ultraviolet irradiance.

were used in the present study. In this study, the cohort included 98 patients treated at the Pathology Department of Dr Juan Noé Crevani Hospital (Arica, Chile) between January 1989 and December 1993 (14). Furthermore, when ozone layer and solar zenith angle (SZA) data were known, the $\mathrm{T}_{\mathrm{VitD}}$ was calculated using the following formula: $T_{\text {VitD }}=20 /($ UVI $\times R$ ), where $\mathrm{R}$ is a quotient of $\mathrm{UV}_{\mathrm{VitD}} / \mathrm{UV}_{\mathrm{Ery}}$. The ratio function of $\mathrm{UV}_{\mathrm{VitD}}$ and $\mathrm{UV}_{\text {Ery }}$ was adjusted using the following equation: $\mathrm{UV}_{\mathrm{VitD}} / \mathrm{UV}_{\text {Ery }}=(2.00524-1.48303) \times \exp (-\mathrm{UVI} / 2.73854)$. In addition, the skin cancer rates (SCR) per 100,000 individuals between 2001 and $2011(14,23)$ were adjusted using the following linear fit equation: $\mathrm{SCR}=(-918.24+1.46) \mathrm{x}$ number of years.

The study was approved by the ethics committee of Servicio de Dermatología, Dr Juan Noé Crevani Hospital (Arica, Chile). The data analyzed in the study were obtained from public databases of Servicio de Dermatología, Dr Juan Noé Crevani Hospital.

\section{Results}

$U V$ light and $U V$ quotient. The present study investigated the association between the risk of skin cancer and mild exposure 

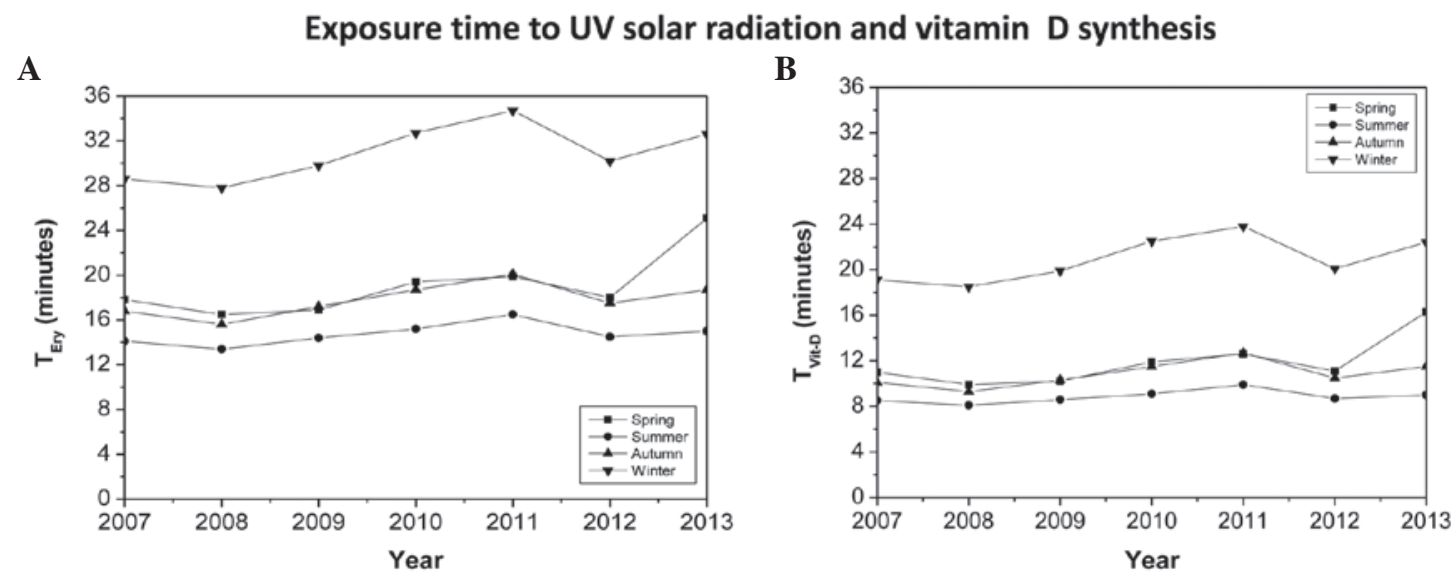

Figure 2. (A) $\mathrm{T}_{\mathrm{Ery}}$ in the four seasons of the year between 2007 and 2013. (B) $\mathrm{T}_{\mathrm{VitD}}$ during the four seasons of the year when only hands and face where directly exposed to direct ultraviolet sunlight (10\%). $\mathrm{T}_{\mathrm{Ery}}$, ultraviolet radiation exposure time required to induce solar erythema; $\mathrm{T}_{\mathrm{VitD}}$, ultraviolet radiation exposure time required to synthesize $1,000 \mathrm{IU}$ vitamin D.

\section{Vitamin $\mathrm{D}$ and skin cancer rates}

A

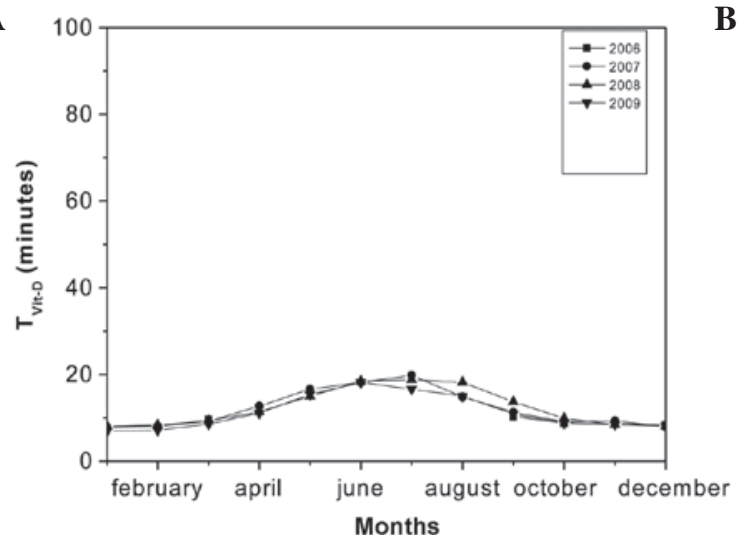

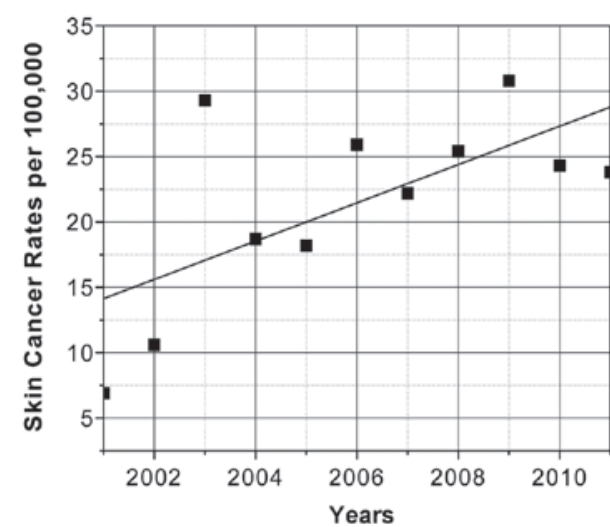

Figure 3. (A) $\mathrm{T}_{\mathrm{VitD}}$ for each month of the year when only exposed hands and face were exposed to direct ultraviolet sunlight (10\% total body surface area). (B) Skin cancer rates per 100,000 individuals in Arica between 2001 and 2011. $\mathrm{T}_{\mathrm{VitD}}$, ultraviolet radiation exposure time required to synthesize 1,000 IU vitamin D.

to UV light in Arica, Chile. The $\mathrm{T}_{\text {Ery }}$ and $\mathrm{T}_{\mathrm{VitD}}$ were calculated to explain the possible effects of insufficient vitamin $\mathrm{D}$ in individuals living at a latitude of $18^{\circ} 18^{\prime} \mathrm{S}$, a longitude of $70^{\circ}$, $26^{\prime} \mathrm{W}$ and a height of $23 \mathrm{~m}$. Fig. 1A displays the highest daily levels of solar UVI versus Julian day (in one year Julian days take the values 1-365), the second scale indicate the years. Solar UVI values were obtained in Arica between September 20, 2006 and November 24, 2011, with the solar UVI fluctuating between 2 and $15.5 \mathrm{~W} / \mathrm{m}^{2}$. Fig. 1B indicates the quotients of $\mathrm{UV}_{\mathrm{VitD}} / \mathrm{UV}_{\text {Ery }}$ as a function of UVI and demonstrates that the quotient varied between 0.5 and 2.0 for UVI values between 0 and $15 \mathrm{~W} / \mathrm{m}^{2}$.

Exposure time of UV radiation and vitamin D synthesis. Fig. 2A reveals the results obtained from calculating the $\mathrm{T}_{\text {Ery }}$ in the four different seasons of the year between 2007 and 2013. It was observed that the $\mathrm{T}_{\text {Ery }}$ varied between $12 \mathrm{~min}$ in the summer and $34 \mathrm{~min}$ in the winter for skin type IV. Fig. 2B displays the mean value $\mathrm{T}_{\mathrm{VitD}}$ per person during the four seasons of the year when only hands and face were directly exposed to UV sunlight (10\% of the surface area of the body). These calcula- tions were obtained between 2007 and 2013, and varied from $8 \mathrm{~min}$ in the summer to $24 \mathrm{~min}$ in the winter.

Vitamin D and skin cancer rate. Fig. 3A indicates the average monthly $\mathrm{T}_{\mathrm{VitD}}$ required for individuals that only exposed their hands and face to direct sunlight. These calculations were made at midday each month between 2006 and 2009. It was observed that the exposure times varied between $8 \mathrm{~min}$ in summer (January-February) and 24 min in winter (June-July). In addition, the calculated $\mathrm{T}_{\mathrm{VitD}}$ data was similar each year. Fig. 3B shows the SCR per 100,000 individuals between 2001 and 2006 (23), and 2007 and 2011 (14). A steady increase was observed, increasing from 6.9 in 2001 to 23.8 in 2011, with the highest rate reaching 30.8 in 2009.

$U V$ index and solar zenith angle. The quotient of $\mathrm{UV}_{\mathrm{VitD}} / \mathrm{UV}_{\text {Ery }}$ as a function of the SZA is displayed in Fig. 4A. This calculation was performed using UVI data obtained in 2007, which behaved similarly to previous years, using an ozone layer thickness of 250 Dobson units (DU). The highest value for this quotient (2.06-2.07) was obtained at a SZA of $<10^{\circ}$, 
Table I. Skin cancer rate and $\mathrm{T}_{\mathrm{VitD}}$ during the four seasons of the year between 2007 and 2011 in Arica, Chile.

\begin{tabular}{|c|c|c|c|c|c|}
\hline \multirow[b]{2}{*}{ Year } & \multirow[b]{2}{*}{ Skin cancer rate/100,000 individuals } & \multicolumn{4}{|c|}{$\mathrm{T}_{\mathrm{VitD}}, \min$} \\
\hline & & Winter & Fall & Spring & Summer \\
\hline 2007 & 30.2 & 19.1 & 11.0 & 10.1 & 8.5 \\
\hline 2008 & 25.4 & 18.5 & 9.9 & 9.3 & 8.1 \\
\hline 2009 & 30.8 & 19.9 & 10.2 & 10.3 & 8.6 \\
\hline 2010 & 24.3 & 22.5 & 11.9 & 11.5 & 9.1 \\
\hline 2011 & 23.8 & 23.8 & 12.6 & 12.7 & 9.9 \\
\hline
\end{tabular}

$\mathrm{T}_{\mathrm{VitD}}$, ultraviolet radiation exposure time required to synthesize $1,000 \mathrm{IU}$ of vitamin $\mathrm{D}$.
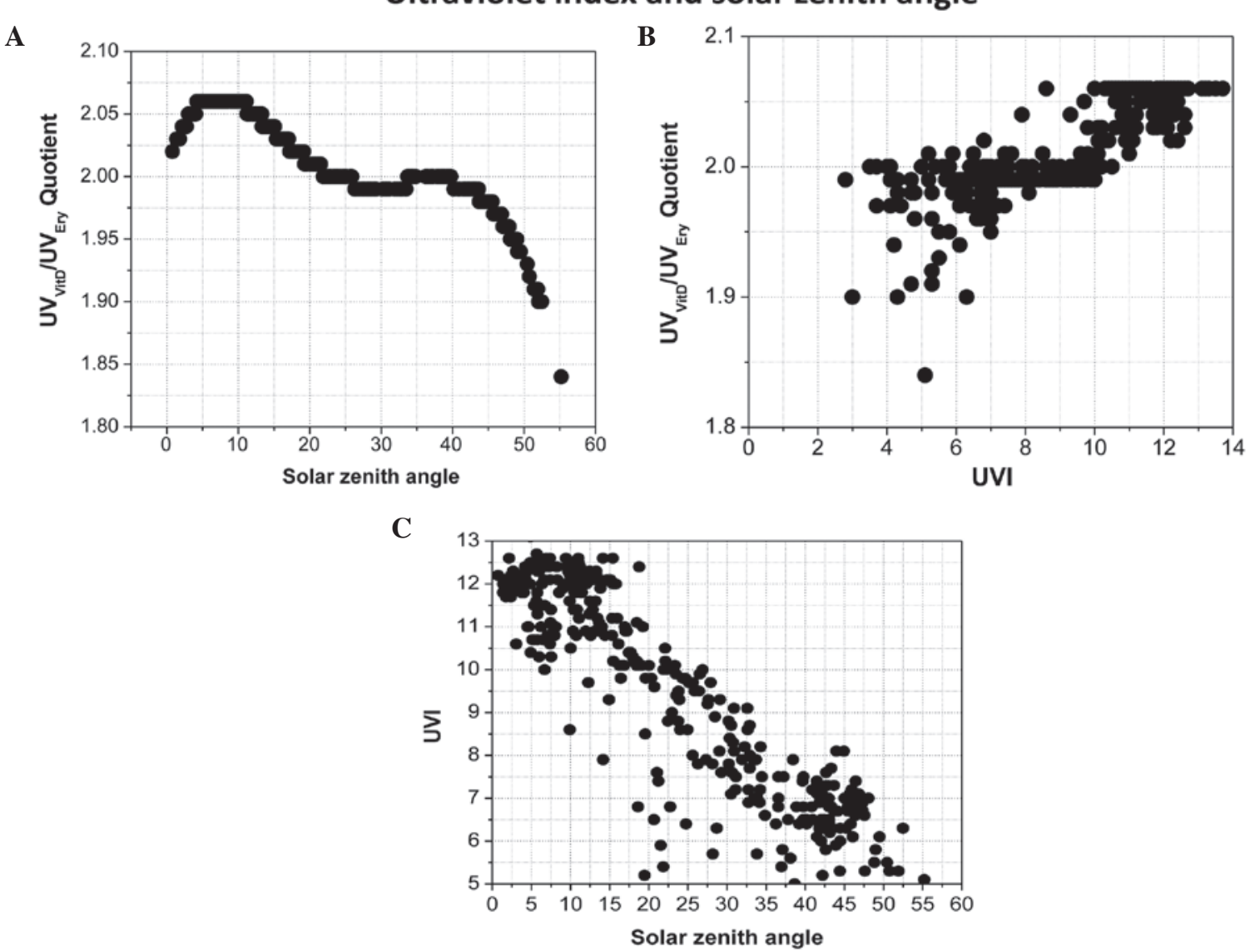

Figure 4. Quotient of $\mathrm{UV}_{\mathrm{VitD}} / \mathrm{UV}_{\mathrm{Ery}}$ (A) as a function of the solar zenith angle and (B) as a function of solar UVI data from 2007, at an ozone layer thickness of 250 Dobson units. (C) Solar UVI as a function of the solar zenith angle between January and July 2007. UV VitD $_{\text {, vitamin D UV irradiation; UV }}$ Ery, erythemal UV irradiance; UVI, ultraviolet index.

whereas the lowest value for this quotient (1.83) was obtained at a SZA of $>50^{\circ}$. The quotient of $\mathrm{UV}_{\mathrm{VitD}} / \mathrm{UV}_{\mathrm{Ery}}$ as a function of UVI data from 2007, with an ozone layer thickness of 250 DU is indicated in Fig. 4B. The highest value for this quotient (2.062.07) had a UVI value of $>10 \mathrm{~W} / \mathrm{m}^{2}$ and the lowest value for this quotient (1.83) had a UVI of $5 \mathrm{~W} / \mathrm{m}^{2}$. Fig. $4 \mathrm{C}$ demonstrates solar UVI as a function of SZA between January and July 2007. The highest UVI value was $12.7 \mathrm{~W} / \mathrm{m}^{2}$ for a SZA that fluctuated between 5 and $20^{\circ}$, with a maximum and minimum value of 5 and $40^{\circ}$, respectively. Table I presents the skin cancer rate and time to synthesize 1000 UI of vitamin D (TVID) during the four seasons of the year between 2007 and 2011 in Arica, Chile. The mean SCR between 2007 and 2011 was calculated as 26.9 per 100,000 individuals.

\section{Discussion}

Arica is located in the northern region of Chile, close to the equator, and is surrounded by desert and ocean (14). Therefore, the quotient calculated from the level of reflective solar UV 
radiation and the incidence of solar UV radiation is generally high (14). Furthermore, the ground surfaces are poorly vegetated, dusty and covered by extended areas of water surface that induce high reflectivity, resulting in high diffuse radiation (14). In addition to receiving high doses of UV solar radiation, the stratospheric ozone layer in this location is lower in comparison with other cities in Chile below the equator, as Arica has a minimum ozone value of 230 DU in the summer and the maximum of 290 DU in September (14). The observed destruction of the ozone layer has intensified research regarding the levels of solar UV irradiance received on the surface of the earth (24). These factors allow incremental increases in solar UV radiation to be measured at different latitudes, which enables the evaluation of potential health consequences for individuals in the population. In addition, these factors have been accompanied by public campaigns to alert the population of the dangers of overexposure to UV (14). However, this issue has sensitized a large number of people to take extreme measures, such as completely avoiding exposure to the sun. Numerous studies have demonstrated the association between poor sun exposure and vitamin D synthesis (9-12). Such insufficiency is associated with various diseases, including melanoma skin cancer, type 1 diabetes, multiple sclerosis, rheumatoid arthritis and inflammatory bowel disease (25).

Incidence rates of skin cancer have significantly increased at equatorial latitudes between 2001 and 2011 (6.9-23.8\%), according to statistics obtained from Arica $(24,26)$. This significant increase is becoming a health issue for those living in this area. A possible reason for this increase in the rate of skin cancer may be due to inadequate levels of vitamin D in the blood plasma. Vitamin D has immune stimulatory and immunosuppressive effects relevant to human and mycobacterium responses (2). It has been reported that low vitamin D levels induce immunomodulation and may affect the association between vitamin $\mathrm{D}$ and tuberculosis (25). The results of the present study demonstrated that at midday, $\mathrm{T}_{\mathrm{VitD}}$ varies between 8 and $24 \mathrm{~min}$ according to the season. Taking these factors into account, the aforementioned exposure times are considered to be ideal condition. However, if exposure occurs at a time other than midday or on a cloudy day, the exposure time should be increased. Therefore, despite high UV levels in this region, a certain proportion of the population appear to be receiving insufficient sunlight exposure to synthesize appropriate vitamin D levels. Furthermore, in high UV sun radiation regions, individuals may work under artificial light or with little exposure to UV radiation. Therefore, the aim of the present study was to compare $\mathrm{T}_{\mathrm{Ery}}$ and $\mathrm{T}_{\mathrm{VitD}}$. It was proposed that these calculations should be determined in different latitudes and UV exposure regions, where the time to vitamin D absorption and synthesis are higher. In addition, special care is recommended regarding the potential harm of inappropriate vitamin D supplementation, as excess vitamin D is associated with immune stimulatory and immune suppressive effects relevant to human antimicrobial responses. Furthermore, vitamin D trials in patients with active tuberculosis should be performed in well-selected populations using adequate vitamin D doses (10). Our previous study reported that skin cancer risk is influenced by UV irradiation in different latitudes (18-20). To the best of our knowledge, there are no previous studies linking vitamin D synthesis and exposure to UV solar radiation in this latitude.
The present study indicated that despite being in an area of high exposure to UV solar radiation, increased rates of skin cancer may also be due to vitamin D deficiency in high risk groups such as post-menopausal women.

\section{Acknowledgements}

The present study was supported by grants from the University of Tarapacá, Arica, Chile (grant no. UTA-4720, 2015, to Professors Miguel Rivas and Elisa Rojas) and FONDECYT (grant no. 1120006; Dr Gloria M. Calaf). The authors would like to thank Mr. Leodan A. Crispin and Mr. Richard Ponce-Cusi for their assistance in the present study.

\section{References}

1. Elwood JM and Jopson J: Melanoma and sun exposure: An overview of published studies. Int J Cancer 73: 198-203, 1997.

2. Holick MF: Vitamin D: Importance in the prevention of cancers, type I diabetes, heart disease and osteoporosis. Am J Clin Nutr 79: 362-371, 2004

3. Mckenzie L, Liley JB and Bjorn LO: UV Radiation: Balancing Risk and Benefits. Photochem Photobiol 85: 88-98, 2009.

4. Garland CF, Comstock GW, Garland FC, Helsing KJ, Shaw EK and Gorham ED: Serum 25-hydroxyvitamin D and colon cancer: Eight year prospective study. Lancet 2: 1176-1178, 1989.

5. Banwell CM, Singh R, Stewart PM, Uskokovic MR and Campbell MJ: Antiproliferative signalling by $1,25(\mathrm{OH}) 2 \mathrm{D} 3$ in prostate and breast cancer is suppressed by a mechanism involving histone deacetylation. Recent Results Cancer Res 164: 83-98, 2003.

6. Grant WB: An ecologic study of dietary and solar ultraviolet-B links to breast carcinoma mortality rates. Cancer 94: 272-281, 2002.

7. Grant WB: An estimate of premature cancer mortality in the U.S. due to inadequate doses of solar ultraviolet-B radiation. Cancer 94: 1867-1875, 2002.

8. Zittermann A, Schleithoff SS, Tenderich H, Berthold HK, Körfer R and Stehle P: Low vitamin D status: A contributing factor in the pathogenesis of congestive heart failure? J Am Coll Cardiol 41: 105-112, 2003.

9. Holick MF: Shedding new light on the role of the sunshine vitamin D for skin health: The lncRNA-skin cancer connection. Exp Dermatol 23: 391-392, 2014.

10. Matkovic V: Calcium metabolism and calcium requirements during skeletal modeling and consolidation of bone mass. Am J Clin Nutr 54: 245S -260S, 1991.

11. Leccia MT: Skin, sun exposure and vitamin D: Facts and controversies. Ann Dermatol Venereol 140: 176-182, 2013 (In French).

12. Ralph AP, Lucas RM and Norval M: Vitamin D and solar ultraviolet radiation in the risk and treatment of tuberculosis. Lancet Infect Dis 13: 77-88, 2013.

13. Ooms ME. Roos JC, Bezemer PD, van der Vijh WJ, Bouter LM and Lips P: Prevention of bone lost by vitamin D supplementation in elderly women: A randomized double blindtrial. J Clin Endoc \& Metab 80: 1052-1085, 1995.

14. Rivas M, Araya MC, Caba F, Rojas E and Calaf GM: Ultraviolet light exposure influences skin cancer in association with latitude. Oncol Rep 25: 1153-1159, 2011.

15. Rivas M, Rojas E and Calaf GM: Prediction of skin cancer ocurrence by ultraviolet solar index. Oncol Lett 3: 893-896, 2012.

16. Rivas M, Rojas E and Calaf GM: Skin cancer risk influenced by ultraviolet solar irradiance. Oncol Lett 7: 483-486, 2014.

17. Rivas M, Leiva C and Rojas E: Estudio de series temporales de energía solar UVB de $305 \mathrm{~nm}$ y espesor de la capa de ozono estratosférico en Arica, norte de Chile. Ingeniare 19: 168-173, 2011 (In Spanish).

18. World Meteorological Organization (WMO): Report of the WMO Meeting of Experts on UV-B Measurements, Data Quality and Standardization Of UV Indices, Les Diablerets. WHO, Geneva, Switzerland, pp36, 1994 (WMO TD no. 625).

19. Fitzpatrick TB: The validity and practicality of sun-reactive skin types I through VI. Arch Dermatol 124: 869-871, 1988.

20. Sachdeva S: Fitzpatrick skin typing. Applications in dermatology. Indian J Dermatol Venereol Leprol 75: 93-96, 2009. 
21. Madronich S, McKenzie RL, Björn LO and Caldwell MM: Changes in biologically active ultraviolet radiation reaching the Earth's surface. J Photochem Photobiol B 46: 5-19, 1998.

22. Peters RD, Krueger AJ, Bhartia PK and Herman JR: Earth probe total ozone mapping spectrometer (TOMS) Data Products User's Guide. NASA Reference Publication 1998-206895. National Aeronautics and Space Administration, Washington, DC, 1998

23. Rivas M, Araya MC, Durán V, Rojas E, Cortes J and Calaf GM: Ultraviolet light exposure and skin cancer in the city of Arica, Chile. Mol Med Rep 2: 567-572, 2009.
24. Bojkov R and Fioletov V: Estimating the global ozone characteristics during the last 30 years. J Geoph Res 100: 16537-16551, 1995.

25. Schwalfenberg GK: Solar radiation and vitamin D: Mitigating environmental factors in autoimmune disease. J Environ Public Health 2012: Article ID 619381, 2012.

26. Moan J, Porojnicu AC, Dahlback A and Setlow RB: Addressing the health benefits and risks, involving vitamin $D$ or skin cancer of increased sun exposure. Proc Natl Acad Sci USA 105: 668-673, 2008 